\title{
Introduction: In Honor of Fred S. Keller
}

\author{
Celia Wolk Gershenson \\ University of Minnesota
}

History of the symposia and celebration. This special section is composed of papers that were presented at the annual meeting of the Association for Behavior Analysis held in May 1989. They are taken from the symposia and celebrations honoring Fred S. Keller on the occasion of his 90 th birthday and commemorating the 40th anniversary in 1990 of the publication of Keller and Schoenfeld's Principles of Psychology. A bit of history is in order.

I recall a sultry August afternoon in Atlanta toward the end of the 1988 ABA meetings. A group of behavior analysts of various ages and persuasions, Fred and Frances Keller among them, had gathered spontaneously to partake of libations and conversation. Someone observed that Fred would turn 90 on January 2nd and that there should be some activity at the ABA meeting in May to mark the occasion. What would be suitable? The consensus reached was that the most appropriate and acceptable celebration would be a series of symposia reflecting Fred's many-faceted contributions to the experimental analysis of behavior. At least one person present even offered to organize one of the symposia. After additional libations, it was noted that Keller and Schoenfeld's Principles of Psychology was published in 1950. All agreed that it would indeed be a wonderful and unique occasion if we could entice Nat Schoenfeld to return to participate in the Keller festivities as well as to celebrate the almost 40th anniversary of the publication of the Keller and Schoenfeld text. During the next few months, a host of letters were exchanged and phone calls made. The cocktail hour conversation was turned into another kind of verbal behavior, actual presentations at ABA. What evolved were six symposia, for the most part organized by the chairs, an invited address presented by Schoenfeld, a panel discussion with Fred Skinner, Fred Keller, and Nat Schoenfeld as participants and Kurt Salzinger as moderator, and a glorious birthday party banquet for Keller arranged by Julie Vargas.

The symposia. The criteria for the selection of topics for the symposia were that they reflect the range of Keller's contributions to the field, the impact of Keller and Schoenfeld's text and its influence on generations of radical behaviorists and others. The participants included colleagues and students of both Keller and Schoenfeld and students of their intellectual offspring. One symposium, chaired by Jim Dinsmoor, was devoted specifically to Principles of Psychology and its influence. Symposia chaired by Sam Deitz and Gil Sherman focused on Keller's contributions to the areas of instructional design, PSI, and education. Another symposium, chaired by Murray Sidman, brought visitors from Brazil who talked about Keller's role in the establishment of behavior analysis in Brazil. A symposium chaired by Robert Thompson provided a glimpse of the ambience, the research, and the intellectual development of Keller and Schoenfeld's "offspring" at Columbia from 1940s through 1960s. A sixth symposium, chaired by Donald Cook, included papers that might be termed miscellaneous, that did not fit into other categories yet illustrated other dimensions of Keller's impact on both basic and applied endeavors. The presentations ranged from informal reminiscences to data-oriented papers. A list of the symposia and the participants is included at the end of this introductory section.

Selection of papers for this issue. Publication of the presentations was discussed from the outset. A number of options were considered. The simplest solution (and the one with the shortest 
delay) was supplied by Sigrid Glenn in a conversation after the last symposium. She suggested that representative papers be included in a special section of this issue of The Behavior Analyst. The five papers selected, reviewed, and prepared for this issue are taken from three symposia, Windows on the World, Keller and Schoenfeld's Principles of Psychology, and Columbia University: Discriminative Stimuli and Establishing Operations. They were chosen in part because they required minimal revision to be appropriate for publication and time was short. Much more importantly, they provide us with a glimpse of the history and the ambience of a department that produced so many active researchers, teachers, and practitioners in the experimental analysis of behavior. A second group of papers will appear in a subsequent issue of The Behavior Analyst.

About the papers. If I were asked for key words or terms that encompass the papers in this section I would choose the three-term contingency. The authors concentrate on the discriminative or antecedent stimuli that set the occasion for the academic and research behavior they describe and the nature of the reinforcing consequences that shaped those behaviors and have maintained them or like behaviors over a number of years. These are five case histories in the training of researchers and teachers.

The order of papers falls into a loose chronological sequence. Jim Dinsmoor was at Columbia during the mid to late 1940s. His paper provides a history of the development of Keller and Schoenfeld's Principles of Psychology, the course in which it was used, and its impact not only on the undergraduate students for whom it was designed but also on the graduate student TAs and instructors who were involved in its implementation. Murray Sidman, who was at Columbia in the late 1940s and early 1950s, presents a view of the atmosphere fostered by Keller and Schoenfeld that served as an impetus for the diverse research emerging from the Columbia laboratories including the beginnings of unsignalled avoidance. Also, we see a picture of what conducting studies before sizable grants were awarded to operant researchers entailed. Bill Stebbins was at Columbia during the middle 1950s. His and David Moody's paper focuses on the influence of the experimental analysis of behavior on related biological disciplines. They draw examples from their own research in animal psychophysics and its implications for neurophysiology and evolutionary biology. Tony Nevin, a student during the late 1950 s and early 1960 s, further elucidates the nature of the environment that served to produce rigorous and persistent researchers and teachers. He highlights the important contributions of two other denizens of the second floor of Schermerhorn Hall, Bill Cumming and Bob Berryman (both deceased), to his education and the focus of his research. Finally, a most appropriate closing paper or grand finale to this section is Bill McGill's appreciation of Fred Keller and what he calls the golden age of Schermerhorn Hall. McGill gives us the perspective of a junior colleague during the late $1950 \mathrm{~s}$. He highlights the influence of those days and Keller on his subsequent career as President of the University of California at San Diego and of Columbia University during the difficult 1960s.

Symposia in honor of Fred Keller's 90th birthday and the almost 40th anniversary of the publication of Keller and Schoenfeld's Principles of Psychology, ABA annual meeting, May 25-28, 1989:

Samuel M. Deitz, Georgia State University, and Cathy Watkins, Auburn University, Chairs: Fred S. Keller at 90: What He Never Knew He Taught Us Kent R. Johnson, Morningside School, Seattle, WA: "A funny thing happened on the way to a degree in government"

John H. Hummel, University of Houston Downtown College: "Pedagogue's decline: COMENIUS R US"

Deborah A. Shanley, Medgar Evers College-CUNY, "FSK, PSI, and SLI"

Henry S. Pennypacker, University of Florida: "He met the challenge of technology transfer" 
Claudia McDade, Jacksonville State University: "Hello, teacher ..."

Donald A. Cook, JHM Corporation, Chair: Windows on the World

Edward W. Schneider, Peacham Pedagogics: "Computer management of individualized instruction"

Celia Wolk Gershenson, University of Minnesota: "Response variability in subject and experimenter"

Donald A. Cook, JHM Corporation: "Morse Code: The hidden legacy"

Arthur W. Snapper, State Systems, Inc.: "Contingencies, notation, and machines"

William J. McGill, Columbia University: "Time past, time present, time future"

James A. Dinsmoor, Indiana University, Chair: "Keller and Schoenfeld's Principles of Psychology

James A. Dinsmoor, Indiana University: "What they added"

William C. Stebbins, University of Michigan: "Concerning the hallmark of a discrimination"

Joseph M. Notterman, Princeton University: "Chaining and programmed instruction"

Thom Verhave, Queens College-CUNY: "K and S as a systematic textbook"

H. McIlvaine Parsons, Essex Corporation, Alexandria, VA: "Conversion by the New Testament"

J. Gilmour Sherman, Georgetown University, Chair: Keller's Influence on Instruction

George Geis, Ontario Institute for Studies in Education, Toronto: "Past imperfect, present conditional: Some research on formative evaluation"
Stuart Margulies, Psychologist, New York: "Shaping up important behavior"

George Semb, University of KansasLawrence: "PSI: A tool for educational research"

Donald A. Cook, JHM Corporation: "PSI: Two unorthodox studies"

J. Gilmour Sherman, Georgetown University: "PSI: Twenty-five years later"

Murray Sidman, New England Center for Autism, Chair: Fred Keller and the Brazilian Connection

Margarida H. Windholz, Julio C. de Rose, Sonia Meyer, and Rachel Rodrigues Kerbauy talk about their work and about Fred Keller's contribution to psychology and behavior analysis in Brazil

Robert L. Thompson, Hunter CollegeCUNY, Chair: Columbia University: Discriminative Stimuli and Establishing Operations

Murray Sidman, New England Center for Autism: "Avoidance at Columbia"

Philip Bersh, Temple University: "Respondent-operant interactions: From the heart to zero operant contingencies"

John J. Boren, National Institute on Drug Abuse: "When Keller was a professor and I was his grad student"

John A. Nevin, University of New Hampshire: "Keller, Schoenfeld, Cumming, and Berryman as instructional stimuli"

Eliot Hearst, Indiana University: "From gambits and timetables to features and gaps" 